\title{
Fertility and the Plough
}

\section{Citation}

Alesina, Alberto Francesco, Paola Giuliano, and Nathan Nunn. 2011. "Fertility and the Plough." American Economic Review 101 (3) (May): 499-503. doi:10.1257/aer.101.3.499. http:// dx.doi.org/10.1257/aer.101.3.499.

\section{Published Version}

doi:10.1257/aer.101.3.499

\section{Permanent link}

http://nrs.harvard.edu/urn-3:HUL.InstRepos:11986333

\section{Terms of Use}

This article was downloaded from Harvard University's DASH repository, and is made available under the terms and conditions applicable to Other Posted Material, as set forth at http:// nrs.harvard.edu/urn-3:HUL.InstRepos:dash.current.terms-of-use\#LAA

\section{Share Your Story}

The Harvard community has made this article openly available.

Please share how this access benefits you. Submit a story.

Accessibility 


\title{
Fertility and the Plough
}

\author{
By Alberto Alesina, Paola Giuliano, and Nathan NunN ${ }^{*}$
}

Recent studies provide evidence that a significant portion of the cross-country variation in female labor force participation and fertility can be explained by cultural norms. ${ }^{\mathbb{1}}$ In a recent paper, we examine the historical origins of these cultural differences (see Alesina, Giuliano, and Nunn 2010). We test the long-standing hypothesis, first developed by Ester Boserup (1970), that different attitudes about gender roles evolved because of differences in the form of agriculture traditionally practiced. In societies with shifting cultivation, agriculture is labor intensive, cultivation uses a hoe or a digging stick, and women actively participate. In contrast, with intensive cultivation, which uses the plough, agricultural work requires significant strength. In these societies men tend to specialize in agriculture and women tend to specialize in home production and other work within the domestic sphere. Boserup argues that the differences in the two types of agriculture resulted in different norms about the natural role of women in society. In societies featuring plough agriculture, gender attitudes typically exhibit less equality regarding the role of men and women in society, and the view that the appropriate role for women is in the domestic sphere is much more common.

In Alesina, Giuliano, and Nunn (2010), we test Boserup's hypothesis by constructing a measure of historic plough use among the ancestors

\footnotetext{
*Alesina: Department of Economics, Harvard University, 1805 Cambridge Street, Cambridge, MA 02138 (e-mail: aalesina@harvard.edu); Giuliano: Anderson School of Management, UCLA, 110 Westwood Plaza, Entrepreneurs Hall C517, Los Angeles, CA 90095 (e-mail: paola.giuliano@anderson.ucla.edu); Nunn: Department of Economics, Harvard University, 1805 Cambridge Street, Cambridge, MA 02138 (e-mail: nnunn@fas.harvard.edu). We are grateful to the discussant Edward Miguel, as well as Raquel Fernandez, Oded Galor, and Judith Hellerstein for valuable comments. We also thank Eva $\mathrm{Ng}$ for research assistance.

${ }^{1}$ See for example Raquel Fernandez and Alessandra Fogli (2006, 2009), who examine second generation US immigrants and show that women's fertility and labor market participation are strongly correlated with the past fertility rates in the immigrants' home countries. See also Nicole Fortin (2005) and Fernandez (2007).
}

of populations today. We show that a history of plough agriculture, today, is associated with attitudes of gender inequality, and with less female participation in the labor force, entrepreneurial activities, and politics. ${ }^{\text {. }}$

In the present paper, we continue this line of enquiry by analyzing the effect of historic plough use on beliefs about fertility. At first, one may expect that societies with historic plough use-and unequal gender roles-will have higher levels of fertility. If women are less likely to participate in market activities outside of the home, this lowers the cost of having children and increases fertility. The current study tests this hypothesis, and finds a surprising result: societies that historically engaged in plough agriculture today have lower fertility, not higher fertility. We show that this relationship is robust and is not caused by statistical outliers or omitted variables bias. We argue, and provide ethnographic evidence, that the finding is explained by the fact that with plough agriculture, children, like women, are relatively less useful in the field. The plough requires strength and eliminates the need for weeding, a task particularly suitable for women and children. This in turn generates a preference for fewer children, lowering fertility.

\section{Data and Estimation Results}

Our empirical analysis begins by examining the cross-country relationship between traditional plough use and fertility today. The measure of historic plough use, which we take from Alesina, Giuliano, and Nunn (2010), is constructed using information, from the Ethnographic Atlas, on the traditional use of the plough among 1,267 ethnic groups worldwide

\footnotetext{
2 The analysis examines variation across countries, districts within countries, and ethnic groups. We show that the results are robust to various estimation strategies and to a large set of historic and contemporary covariates. See Alesina, Giuliano, and Nunn (2010) for full details.
} 
Table 1-Historic Plough Use and Fertility Today: OLS and IV Estimates

\begin{tabular}{lcccccccc}
\hline \hline & \multicolumn{9}{c}{ OLS } & \multicolumn{7}{c}{ IV } \\
\cline { 2 - 9 } & \multicolumn{1}{c}{ Dependent variable: Total fertility rate } \\
\cline { 2 - 9 } & $(1)$ & $(2)$ & $(3)$ & $(4)$ & $(5)$ & $(6)$ & $(7)$ & $(8)$ \\
\hline Historic plough use & $-1.094 * * *$ & $-0.840 * * *$ & $-0.921 * * *$ & $-0.770 * * *$ & $-1.539 * *$ & $-1.628^{*}$ & $-1.687 *$ & $-1.731^{*}$ \\
& $(0.278)$ & $(0.245)$ & $(0.292)$ & $(0.254)$ & $(0.740)$ & $(0.840)$ & $(0.894)$ & $(0.967)$ \\
Continent fixed effects & No & Yes & No & Yes & No & Yes & No & Yes \\
FLFP controls & No & No & Yes & Yes & No & No & Yes & Yes \\
Observations & 160 & 160 & 158 & 158 & 158 & 158 & 156 & 156 \\
$R^{2}$ & 0.65 & 0.77 & 0.69 & 0.79 & 0.66 & 0.78 & 0.68 & 0.78 \\
\hline
\end{tabular}

Notes: The table reports OLS and IV estimates, with robust standard errors in parentheses. The unit of observation is a country. All regressions include historic controls (agricultural suitability, the presence of domesticated animals, the fraction of land that was tropical, political development, and economic development), and the natural log real per capita income. "FLFP controls" indicates a control for each country's female labor force participation rate, as well as the rate squared.

*** Significant at the 1 percent level.

** Significant at the 5 percent level.

* Significant at the 10 percent level.

(see George Peter Murdock 1967). ${ }^{\text {B }}$ The ethnographic data are then matched to current populations using the global distribution of 7,612 language groups from the 15 th edition of the Ethnologue and the global distribution of population densities from the 2000 Landscan database. An important point is that the procedure links the past to the present using language and ethnicity, not geography. This is relevant because we are interested in culture, which is geographically mobile. In the end, the construction procedure generates a measure of the fraction of a country's ancestors who traditionally engaged in plough agriculture.

The outcome of interest is a country's current total fertility rate, which we view as an objective measure that captures a country's attitude toward fertility ${ }^{\boxplus}$ In the analysis, we are careful to control for other factors, besides cultural beliefs, that also affect fertility. These include: the level of economic development, measured by the natural log of a country's real per capita GDP, and a country's rate of female labor force participation. We also control for a rich set of historic

\footnotetext{
${ }^{3}$ The ethnographic data are primarily from observations recorded in the late nineteenth and early twentieth centuries. See Alesina, Giuliano, and Nunn (2010) for further details.

${ }^{4}$ The data are from the United Nations Demographic Yearbook. The total fertility rate is calculated as the average number of children a hypothetical cohort of women, from the ages of 15 to 49 , would have at the end of their reproductive period if they were subject during their whole lives to the age-specific average fertility rates of a given country in a given time period. The measure is from 2007.
}

ethnographic controls that measure the historic characteristics of a country's ancestors in the late nineteenth and early twentieth century and are constructed using the same procedure as for the plough variable. The controls include: the presence of domesticated bovine or equine animals; the presence of tropical or subtropical climate; the number of levels of political hierarchy beyond the local community (political complexity); and a measure of the sophistication of settlement (economic complexity). For full details of all variables see Alesina, Giuliano, and Nunn (2010).

Estimation results are reported in Table 1. Columns 1 and 2 present estimates without and with continent fixed effects. The estimates show a strong negative relationship between the historic use of the plough and fertility today. According to the estimated magnitudes from column 1, a one-standard-deviation increase in historic plough use is associated with a decline in fertility of 0.52 children, which is equal to 17 percent of the sample's mean fertility. ${ }^{1}$ To ensure that the estimates are not biased by any effect of the plough on female labor force participation, we include a quadratic control for a country's current female labor force participation rate (columns 3 and 4). The estimates are similar, although slightly smaller in magnitude.

5 The beta coefficients for the regressions without and with continent fixed effects are -0.33 and -0.25 , respectively. 


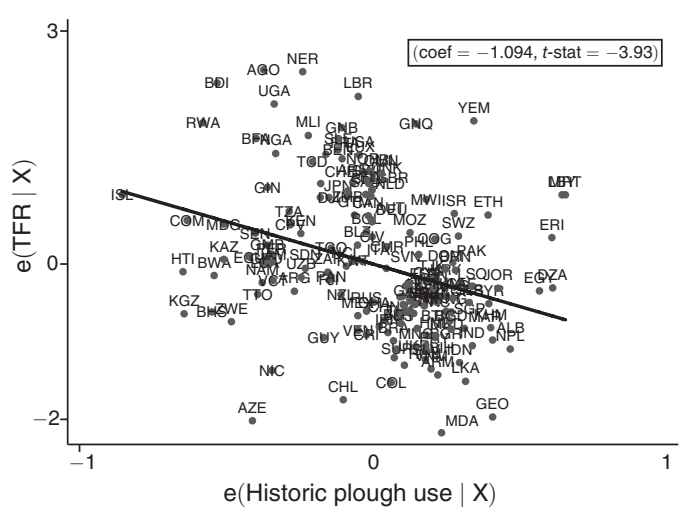

Figure 1. Partial Correlation Plot (Column 1 of Table 1)

The finding of a negative relationship between historic plough use and fertility contradicts the expectation that because historic plough use resulted in less female participation outside of the home, it generated higher fertility. There are a number of potential explanations for this puzzling finding. First, the results could be driven by a small number of unimportant countries. Figure 1, which reports the partial correlation plot from column 1, shows that this is not the case. The relationship appears to be general and not driven by outliers.

It is also possible that the estimates are spurious and driven by omitted variables. An obvious potentially omitted factor is the level of economic development. If plough societies are (and/or were) more developed, then the negative relationship between development and fertility might account for the negative relationship between historic plough use and fertility today. However, our specifications already include a number of measures of economic development, both current and historical. Therefore, we feel that this explanation is unlikely. This being said, to further address this, and to address concerns of omitted variables bias more generally, we provide IV estimates of the effect of the plough on fertility.

Following Alesina, Giuliano, and Nunn (2010), we exploit the variation in historic plough use that arose from differences in societies' geoclimatic conditions, which affected whether crops that potentially benefitted from the plough were cultivated. As Frederic L. Pryor (1985) explains, because of differences in the length of the cropping season, the amount of land required for cultivation, and the characteristics of the soil (slope, depth, rockiness, etc.), crops differ significantly in the extent to which the use of the plough improves productivity. In his study, Pryor identifies crops as being either plough-positive (cultivation greatly benefits from the plough) or plough-negative (cultivation benefits less from the plough).

As in Alesina, Giuliano, and Nunn (2010), we use as instruments the average geoclimatic suitability of ancestors' locations for growing: (i) sorghum and millet (two plough-negative cereal crops) and (ii) wheat and rye (two plough-positive cereal crops), This identification strategy relies on the assumption that, holding constant overall crop productivity (which we control for), the distinction between plough-positive and plough-negative geoclimatic environments impacts fertility only through the plough.

IV estimates are reported in columns 5-8 of Table 1. The IV estimates also show that historic plough use is associated with lower fertility today ${ }^{8}$ The consistency of the OLS and IV estimates make it unlikely that the negative relationship between historic plough use and fertility is due to omitted variables bias.

In our view, the most likely explanation for the counterintuitive result is as follows. It is true that the plough caused women to specialize in work within the home, and this should have decreased the costs of childcare, resulting

\footnotetext{
${ }^{6}$ Plough-positive crops, which typically require extensive land preparation over a large surface area and in a very short period of time, include wet rice, barley, wheat, rye, and teff. Plough-negative crops, which include crops that require relatively little land to produce a sufficient amount of food, crops that can be grown in rocky or sloped land, and crops with seeds that easily take root (even in shallow soils), include tree crops, root crops, maize, millet, and sorghum (Pryor 1985, p. 732).

${ }^{7}$ For each historic ethnic group, the centroid of their historic location is known. We use the fraction of land within a 200-kilometer radius of the centroid that can grow each crop as the measure of ancestors' suitability. Information on the suitability of locations across the globe for cultivating various crops is from FAO's GAEZ 2002 database.

${ }^{8}$ Because of space constraints we do not report the first stage estimates. The first stage of the IV shows that suitability for the cultivation of plough-positive cereals is positively correlated with the adoption of the plough, while suitability for the cultivation of plough-negative cereals is negatively correlated with the plough. In all specifications, the difference between the two coefficients is statistically significant at the 1 percent level.
} 
in norms of greater fertility. However, the benefit to having children was also affected by the plough. Since hoe agriculture (relative to intensive plough agriculture) was relatively more suitable for participation by women and children, and because this form of agriculture was relatively labor intensive, the demand for additional labor, including children, was greater under hoe agriculture than under plough agriculture. Therefore, there were two counteracting forces: the plough decreased the cost of having children, but it also decreased the benefit. Our finding that societies that historically practiced plough agriculture today have lower rates of fertility suggests that the lower benefit from the plough was more important than the lower cost.

If this explanation is correct, then we should observe that historically societies that engaged in plough agriculture had preferences for lower fertility. We are able to test this using ethnographic information from Murdock and Douglas R. White's (1969) Standard Cross-Cultural Sample (SCCS), which contains information on 186 societies globally. The sample includes a measure of preferences for children (variable v950) among 47 of the 186 societies for which data are available. Societies fall into one of three categories: (i) those with a preference to have very few children, (ii) those with no clear preference for the number of children, and (iii) those with a preference for a large number of children. Based on this classification, we create a variable that takes on the values of 1,2 , or 3 , and is increasing in a preference for more children. The correlation between this variable and an indicator that equals one if the society historically used the plough (variable v243) is -0.31 , which is significant at the 5 percent level. Even examining within-continent variation only (i.e., controlling for continent fixed effects), one continues to find a statistically significant relationship of a similar magnitude (the beta coefficient is -0.34). This finding is consistent with our explanation that plough agriculture reduced the benefit of having children (since they were less useful in the fields), and this resulted in a preference for fewer children, which continues to persist today.

\section{Is Cultural Transmission the Channel?}

Implicit in our hypothesis is the assumption that the link between past plough use and fertility today is explained by cultural persistence. However, we have not yet shown this. Past plough use may have also affected the evolution of formal laws and institutions, like tax structures or parental leave laws, which affect the cost of having children and fertility. Therefore, the effect might be through domestic institutions, not cultural persistence.

In an attempt to identify cultural transmission as the mechanism, we examine migrants living within the United States. Migrants face the same markets and institutions (since they are all in the US), but they have different cultural backgrounds (and different histories of cultural transmission). Therefore, if we find a persistent impact of the plough among immigrants living in the US, we can be more confident that the effect we are identifying is through cultural transmission.

Our sample, which is from the 1970 census, includes first- and second-generation married immigrant women. We identify the cultural heritage of second-generation immigrants using the father's country of origin. ${ }^{\text {g }}$ Our outcome variable of interest is the number of children ever born to the woman. The estimating equation includes the following control variables: a quadratic for age, years of educational attainment, employment status fixed effects (employed, unemployed, or out of the labor force), and the natural log of the individual's income. We also control for the following characteristics of the woman's husband: a quadratic for his age, years of education, employment status fixed effects, and the natural log of his income. All regressions also include state and metropolitan status fixed effects, and the natural log of the per capita GDP of the immigrant's country of origin.

OLS and IV estimates are reported in Table 2. As in the cross-country setting, we continue to find a negative association between immigrants' fertility and a tradition of plough agriculture. According to the estimates from column 1, a onestandard-deviation increase in historic plough use is associated with a decline of 0.21 children, which is equivalent to 9 percent of mean firstgeneration immigrant fertility. The results are slightly higher for second-generation immigrants

\footnotetext{
${ }^{9}$ We use the census because, unlike the CPS, it reports the number of children a woman has. We choose 1970 because this is the last year in which the census asks individuals their parents' country of origin.
} 
TABLE 2-OLS AND IV ESTIMATES:

Historic Plough Use and Immigrant Fertility

\begin{tabular}{ccccc}
\hline \hline & \multicolumn{3}{c}{ Dependent variable: Number of children } \\
\cline { 2 - 5 } & \multicolumn{2}{c}{ OLS } & \multicolumn{2}{c}{ IV } \\
\cline { 2 - 5 } & $\begin{array}{c}\text { First } \\
\text { generation }\end{array}$ & $\begin{array}{c}\text { Second } \\
\text { generation }\end{array}$ & $\begin{array}{c}\text { First } \\
\text { generation }\end{array}$ & $\begin{array}{c}\text { Second } \\
\text { generation }\end{array}$ \\
\cline { 2 - 5 } & $(1)$ & $(2)$ & $(3)$ & $(4)$ \\
\hline Historic & $-0.620^{* *}$ & $-1.261^{* * *}$ & $-1.050^{* * *}$ & $-1.555^{* * *}$ \\
plough use & $(0.245)$ & $(0.101)$ & $(0.218)$ & $(0.193)$ \\
Observations & 19,727 & 31,658 & 19,727 & 31,658 \\
$R^{2}$ & 0.22 & 0.17 & 0.22 & 0.17 \\
\hline
\end{tabular}

Notes: Estimates are reported with standard errors clustered at the country level in parentheses. The unit of observation is a US immigrant. Each regression includes individual controls (age, age squared, educational attainment, labor market status fixed effect, and log income), husband controls (husband's age, age squared, educational attainment, labor market status fixed effects, and log income), historic country controls (agricultural suitability, the presence of domesticated animals, the fraction of land that was tropical, political development, and economic development), log per capita GDP in the country of origin, state fixed effects, and metropolitan status fixed effects.

*** Significant at the 1 percent level.

** Significant at the 5 percent level.

* Significant at the 10 percent level.

(column 2). A one-standard-deviation increase in historic plough use is associated with a decline of 0.33 children (which is 12 percent of the mean of second-generation immigrant fertility). The IV estimates are similar, but with coefficients that are slightly larger in magnitude.

Overall, the immigrant estimates are approximately half the magnitude of the cross-country estimates. This is expected since the cross-country analysis captures cultural transmission as well as other channels of persistence (e.g., domestic institutions), while the immigrant regressions captures only the cultural channel.

\section{Conclusions}

This paper has provided evidence that the form of agriculture traditionally practiced-intensive plough agriculture versus hoe agricultureaffected historic norms and preferences about fertility, and that these norms persist, affecting observed fertility around the world today.

We find a negative correlation between historic plough use and total fertility rates today across countries and among first- and secondgeneration immigrants in the US. We argue that the explanation for this result lies in the fact that children (like women) are less useful for plough agriculture. The plough requires strength and obviates the need for weeding, a task particularly suitable for women and children. Therefore, where plough agriculture was practiced, the cost of having children may have been lower (because women were more confined to the home), but the benefit of children was also lower (since they were less useful in agriculture). We also show that, consistent with this explanation, societies that historically used the plough were also more likely to have a preference for fewer children.

\section{REFERENCES}

Alesina, Alberto, Paola Giuliano, and Nathan Nunn. 2010. "On the Origins of Gender Roles: Women and the Plough." Unpublished.

Boserup, Ester. 1970. Woman's Role in Economic Development. London: George Allen \& Unwin Ltd.

-Fernandez, Raquel. 2007. "Alfred Marshall Lecture: Women, Work, and Culture." Journal of the European Economic Association, 5(2-3): 305-32.

-Fernandez, Raquel, and Alessandra Fogli. 2006. "Fertility: The Role of Culture and Family Experience." Journal of the European Economic Association, 4(2-3): 552-61.

-Fernandez, Raquel, and Alessandra Fogli. 2009. "Culture: An Empirical Investigation of Beliefs, Work, and Fertility." American Economic Journal: Macroeconomics, 1(1): 14677.

-Fortin, Nicole M. 2005. "Gender Role Attitudes and the Labour-Market Outcomes of Women across OECD Countries." Oxford Review of Economic Policy, 21(3): 416-38.

Murdock, George Peter. 1967. Ethnographic Atlas. Pittsburgh: University of Pittsburgh Press.

-Murdock, George Peter, and Douglas R. White. 1969. "Standard Cross-Cultural Sample." Ethnology, 8: 329-69.

-Pryor, Frederic L. 1985. "The Invention of the Plow." Comparative Studies in Society and History, 27(4): 727-43. 